\title{
MULTIBAND RING SHAPED FRACTAL MIMO ANTENNA
}

\author{
K. Sumathi ${ }^{1}$, B. Tharini ${ }^{2}$, K.C. Charumathy ${ }^{3}$ and C. Hema ${ }^{4}$ \\ ${ }^{I}$ Department of Electronics and Communication Engineering, Sri Krishna College of Technology, India \\ ${ }^{2,3,4}$ Department of Electronics and Communication Engineering, Dr. Mahalingam College of Engineering and Technology, India
}

\begin{abstract}
A Ring shaped multiband fractal $2 \times 2$ MIMO antenna is proposed. The monopole antenna supports applications such as Bluetooth, GPS and PCS. The proposed antenna is fed with microstrip line feed. The antenna is designed with two different orientations $0^{\circ}$ fractal ring antenna and $180^{\circ}$ shifted fractal ring antenna. The antenna is simulated on 2D EM-simulator of ADS software. FR4 substrate is used and the overall size of the designed antenna is $70 \mathrm{~mm} \times 45.3 \mathrm{~mm} \times 1.6 \mathrm{~mm}$. The antenna is designed to operate for multiple frequencies with increase in gain, directivity, bandwidth and radiation efficiency. The 0 Fractal Ring configuration is better in terms of gain compared with 180 ring design.
\end{abstract}

Keywords:

Ring Antenna, MIMO, Fractal, Multiband

\section{INTRODUCTION}

Antennas are the first and the foremost part of the communication system. According to IEEE definition, "an antenna is a means for radiating and receiving radio waves". The rapid evolution in wireless technology the ability to communicate with people has evolved remarkably. MIMO (Multiple Input Multiple Output) is used for wireless communication. MIMO systems can achieve significantly higher data rate than SISO. MIMO is used to enhance the performance of a single data signal, such as beamforming and diversity. Fractals are geometric shapes that repeat itself over a variety of scale sizes so the shape looks the same when viewed at different scales. They can improve the performance of antenna and antenna arrays. Fractal arrangement can combine the robustness of a random array and the efficiency of a regular array, with a quarter of the number of elements. Fractal bridges the gap because they have short-range disorder and long- range order.

This paper attempts at designing a fractal antenna which resonates at multiple frequencies. It is designed to serve modern wireless service such as Bluetooth, Wireless Local Area Network (WLAN) and Personal Communication System (PCS). Measured results are presented to validate the antenna performance.

Many research works have been carried out to improve the gain and bandwidth of MIMO antenna. Firmansyah et al. [9] designed and analysed conventional MIMO antenna (C-MA), ring parasitic MIMO antenna (RP-MA), and circular parasitic MIMO antenna (CP-MA). Here the antenna is designed at a centre frequency of $2.5 \mathrm{GHz}$ on FR4 substrate. The overall size of the antenna is $50 \mathrm{~mm} \times 130 \mathrm{~mm} \times 23.2 \mathrm{~mm}$.

Srivastava et al. [4] addressed an O-shaped multiband monopole antenna under there different orientations $\left(0^{\circ}, 90^{\circ}\right.$ and $180^{\circ}$ ). The antenna resonates for multiband operation hence useful for wireless communication. The antenna is designed on
FR4 substrate. The overall geometric dimension of the antenna is $60 \mathrm{~mm} \times 50 \mathrm{~mm}$.

Yang et al. [6] presented a dual band Multiple Input Multiple Output (MIMO). The antenna configuration consists of three inverted F antennas (IFA's) loaded with lumped inductors designed by The antenna elements along with lumped inductor can cover GSM 1800/1900, UMTS2100 and LTE700/2300/2500 bands. Four L stubs are connected under the IFA's with the ground plane. The overall geometric dimension of the antenna is $140 \mathrm{~mm} \times 70 \mathrm{~mm} \times 1 \mathrm{~mm}$.

Malviya et al. [7] proposed $2 \times 2$ circularly polarised MIMO antenna with power divider which resonates at $5.8 \mathrm{GHz}$ IEEE 802.11 WLAN for NLOS communication. Here rectangular slots are etched at the centre of the patch. The proposed MIMO antenna covers 5.49-6.024GHz, the CP antenna achieves circular polarisation. The antenna is fabricated on FR4 dielectric substrate. The overall size of the antenna is $27.69 \mathrm{~mm} \times 97 \mathrm{~mm}$ [7].

Mitra et al. [10] proposed a compact two element MIMO antenna system for WLAN applications which resonates at 5.4GHz. Here Rogers RT Duroid $5880^{\mathrm{TM}}$ is used as a substrate. The overall size of the antenna is $30 \mathrm{~mm} \times 50 \mathrm{~mm} \times 1.6 \mathrm{~mm}$. Co-axial feeding is employed here.

Singh et al. [2] analysed the MIMO antenna system for compensating the users induced loss. The paper addresses the OTA performance of the MIMO antenna system and influence on OTA performance of LTE terminal. This paper addresses the reduction in total radiated power and total isotropic sensitivity of the MIMO antenna system is due to the introduction of extra antenna. The overall size of the antenna is $110 \mathrm{~mm} \times 50 \mathrm{~mm} \times 1 \mathrm{~mm}$.

$\mathrm{Tu}$ et al. [3] suggested a dual band MIMO system with enhancement in isolation and WLAN application. This MIMO resonates for two resonant frequencies $2.6 \mathrm{GHz}$. $7 \mathrm{GHz}$ using Defected Ground Structure (DGS). The antenna is designed on FR4 Substrate. The antenna consists of $1 \times 2$ rectangular patches and two double rectangular DGS and $1 \times 7$ EBG structure between antenna elements. The overall size of the antenna is $24 \mathrm{~mm} \times 17 \mathrm{~mm}$.

Babu and Anuradha [5] proposed a compact MIMO antenna for decreasing the mutual coupling as well as to increase the return loss. Here rectangular slots are made at the square patch. The antenna is suitable for WLAN application. The antenna resonated for multiband. This antenna is designed on FR4 substrate. The overall dimension of the antenna is $60 \mathrm{~mm} \times 40 \mathrm{~mm}$.

Ali et al. [1] proposed a very compact size MIMO antenna. This antenna consists of two radiators with partial ground plane and is designed on FR4 substrate. The proposed antenna is designed with a decoupling structure for increasing isolation. Microstrip Multimode Resonator (MMR) is used as decoupling 
structure which acts as band stop filter. The overall size of the antenna is $4 \mathrm{~cm} \times 4 \mathrm{~cm}$.

Pahadsingh and Sahu [8] designed a MIMO system using cylindrical Dielectric Resonator Antenna (CDRA). Two CDRA's are integrated on the radiator to form the proposed antenna. Triband operation is targeted using $\mathrm{T}$ feed microstrip. The antenna is on Roger substrate. The overall geometrical dimension of the antenna is $35 \mathrm{~mm} \times 52.2 \mathrm{~mm}$. This integrated design is suitable for CR applications.

\section{ANTENNA DESIGN}

An O-shaped fractal multiband monopole antenna is designed with the following specifications. An O-shaped MIMO antenna is designed that envelopes the present day wireless communication application bands. The proposed antenna is uses FR-4 as substrate with relative permittivity $\varepsilon_{r}=4.4$, thickness $h=1.6 \mathrm{~mm}$. The layout is as shown in the Fig.1. The antenna is simulated using ADS software. The outer radius of the fractal ring is calculated from,

$$
R=\gamma / 4
$$

The width of the ring is calculated to be $3 \mathrm{~mm}$ to match the 50 ohm impedance.

$$
\begin{aligned}
& \gamma=\frac{c}{f \sqrt{n_{r}}} \\
& n_{r}=\frac{\varepsilon_{r}+1}{2}
\end{aligned}
$$

where,

$c$ - velocity of light in vacuum

$f$ - resonating frequency

$n_{r}$ - relative permittivity of the substrate

$R$ - Radius of the ring

Using the above formulas each ring is designed to resonate at different frequencies. Here $\mathrm{O}$-shaped fractal antenna is designed with different orientations. The first ring resonates at $2.8 \mathrm{GHz}$, second ring resonates at $3.5 \mathrm{GHz}$ and similarly the other rings are designed.

\section{DESIGN PARAMETERS}

The parameters used for the design of fractal ring antenna are given in Table.1. Here, $r_{1}, r_{2}, r_{3}, r_{4}, r_{5}$ and $r_{6}$ indicate the radius of the fractal ring. $l$ and $b$ indicates the length and height of the ground plane respectively. The $h$ and $w$ indicates the height and width of the feedline of the radiating patch. The distance between the two fractals is denoted as $d$ in MIMO configuration.

Table.1. Design Parameters

\begin{tabular}{|c|c|}
\hline Length, Width and radius & Units in mm \\
\hline$r_{1}$ & 16 \\
\hline$r_{2}$ & 13 \\
\hline$r_{3}$ & 10 \\
\hline$r_{4}$ & 7 \\
\hline
\end{tabular}

\begin{tabular}{|c|c|}
\hline$r_{5}$ & 4 \\
\hline$r_{6}$ & 1 \\
\hline$l$ & 60 \\
\hline$h$ & 13.08 \\
\hline$b$ & 13 \\
\hline$w$ & 3 \\
\hline$d$ & 34 \\
\hline
\end{tabular}

\section{DESIGN CONFIGURATION}

The radiating patch consists of $\mathrm{O}$-shaped fractal ring with $0^{\circ}$ and $180^{\circ}$ orientation. In the first iteration, two circles of radius $r_{1}$ and $r_{2}$ are made to form a ring in addition to a ground plane. In the second iteration, the second ring is blended with the first ring such that the lower part of both the ring coincides. In the third iteration, the third ring is blended with the first two rings such that the lower portion of the rings coincides. In the fourth iteration, the fourth ring is blended with the first three rings such that the lower portion of the rings coincides. In the fifth iteration the fifth ring is blended with the first four rings such that the lower portion of the rings coincides with each other. The upper gap between the rings should be $3 \mathrm{~mm}$.

The brown colour indicates the radiating patch structure and green colour indicates the ground plane. As per the design parameters the Single $0^{\circ}$ Fractal Ring Antenna is designed and shown in Fig.1.

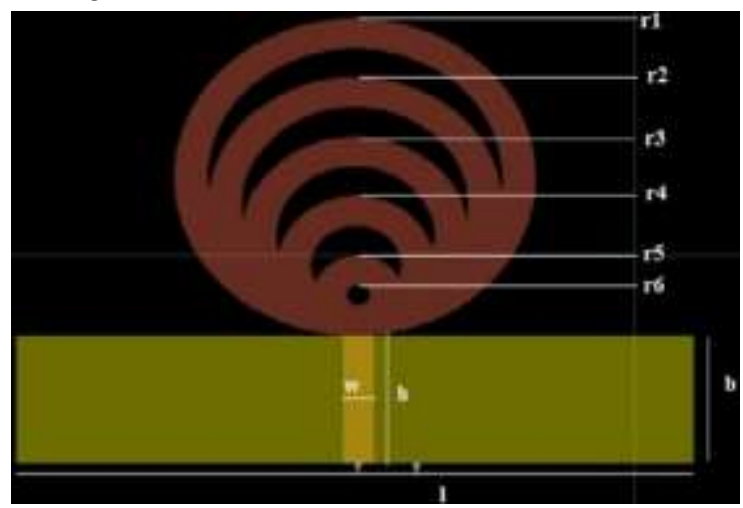

Fig.1. Design layout of single $0^{\circ}$ Fractal Ring Antenna

The $0^{\circ}$ Fractal Ring MIMO Antenna is depicted in Fig.2. The distance $d$ between the antennas is $34 \mathrm{~mm}$.

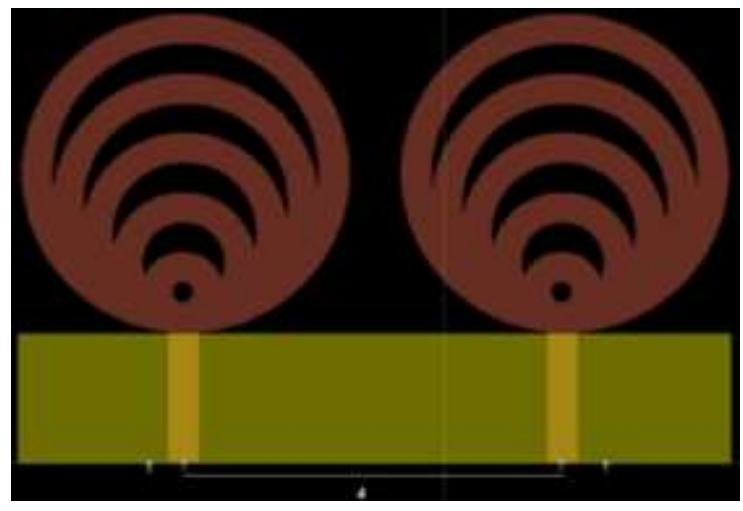

Fig.2. Design layout of $0^{\circ}$ Fractal Ring MIMO Antenna 
The $180^{\circ}$ Fractal Ring Antenna is obtained by shifting the $0^{\circ}$ Fractal Ring Antenna. As per the design parameters the Single $180^{\circ}$ Fractal Ring Antenna and $180^{\circ}$ Fractal Ring MIMO Antenna is given in Fig.3 and Fig.4 respectively.

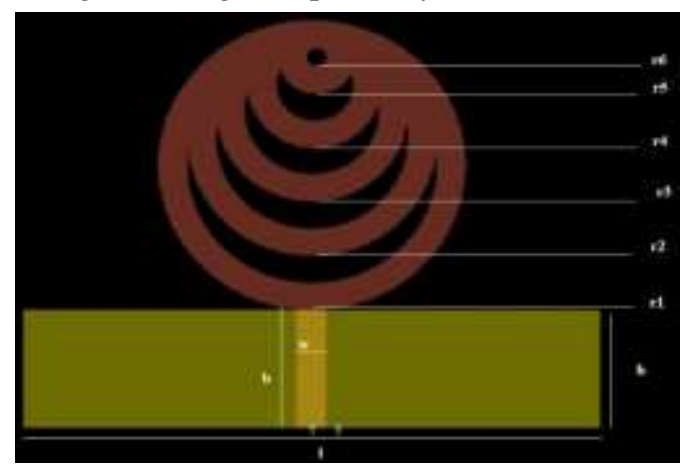

Fig.3. Design layout of Single $180^{\circ}$ Fractal Ring Antenna

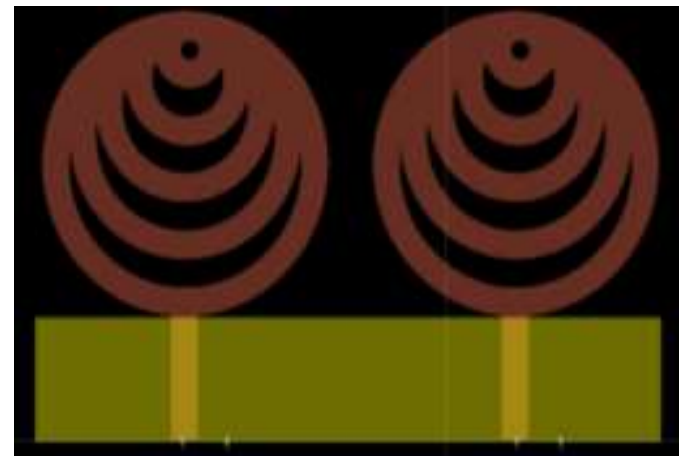

Fig.4. Design layout of $180^{\circ}$ Fractal Ring MIMO Antenna

\section{SIMULATION RESULTS}

\section{$5.10^{\circ}$ FRACTAL RING ANTENNA}

The Fig.5(a) and Fig.5(c) represents the return loss of Single $0^{\circ}$ fractal ring antenna and $0^{\circ}$ fractal ring MIMO antenna. Here $m_{1}, m_{2}, m_{3}, m_{4}$ and $m_{5}$ denote the markers indicating the return loss of the respective antennas.

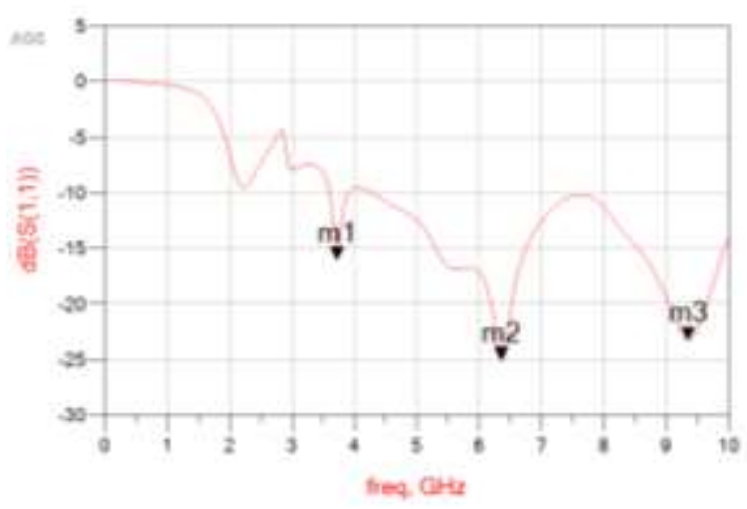

Fig.5(a). Single $0^{\circ}$ fractal ring antenna

The Fig.5(a) shows the return loss of single $0^{\circ}$ fractal ring antenna resonates at three frequencies $3.5 \mathrm{GHz}, 6.3 \mathrm{GHz}$ and $9.3 \mathrm{GHz}$ with return losses $-16.05 \mathrm{~dB},-25.063 \mathrm{~dB}$ and $-23.242 \mathrm{~dB}$ respectively.

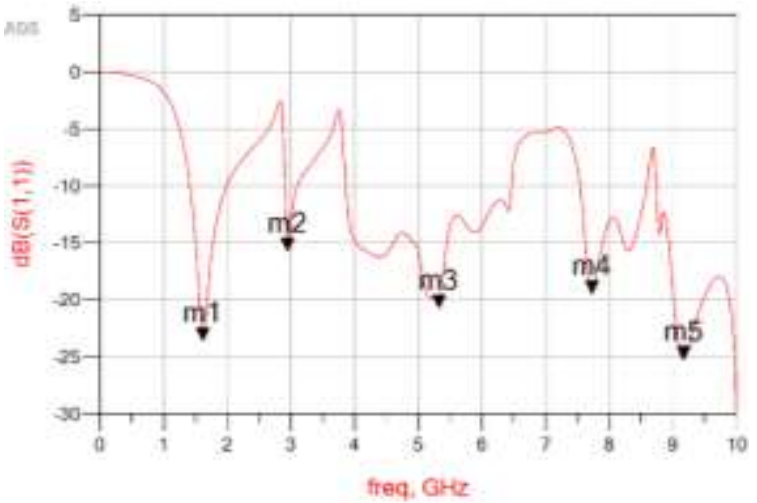

Fig.5(b). $0^{\circ}$ Fractal Ring MIMO Antenna

The Fig.5(b) shows the return loss of single $0^{\circ}$ fractal ring MIMO antenna resonating at five frequencies $1.5 \mathrm{GHz}, 3 \mathrm{GHz}$, $5.18 \mathrm{GHz}, 7.57 \mathrm{GHz}$ and $9.1 \mathrm{GHz}$ with return losses $23.639 \mathrm{~dB}$, $15.76 \mathrm{~dB},-20.770 \mathrm{~dB},-19.487 \mathrm{~dB}$, and $-25.257 \mathrm{~dB}$ respectively.

\section{$5.2180^{\circ}$ FRACTAL RING ANTENNA}

The Fig.5(c) and Fig.5(d) represents the return loss of Single $180^{\circ}$ Fractal Ring Antenna and $180^{\circ}$ Fractal Ring MIMO Antenna.

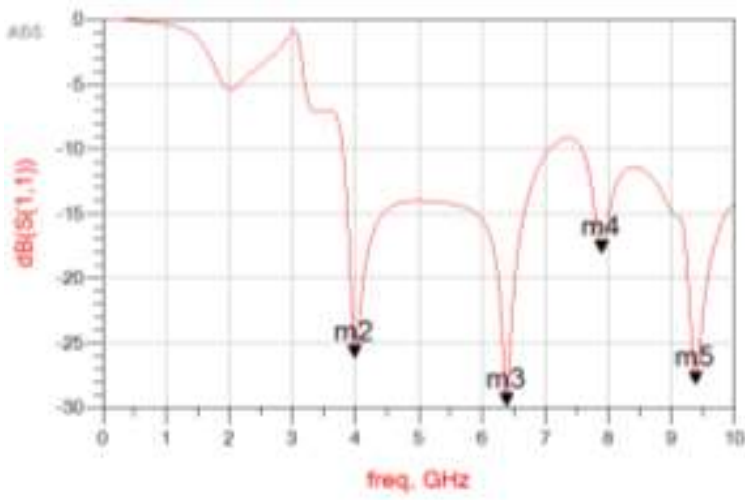

Fig.5(c). Single $180^{\circ}$ Fractal Ring Antenna

The Fig.5(c) shows the return loss of single $180^{\circ}$ Fractal Ring MIMO Antenna resonating at frequencies $4 \mathrm{GHz}, 6.45 \mathrm{GHz}$, $7.9 \mathrm{GHz}$ and $9.47 \mathrm{GHz}$ with return losses $-26.160 \mathrm{~dB},-29.855 \mathrm{~dB}$, $-18.060 \mathrm{~dB}$ and $-28.207 \mathrm{~dB}$ respectively.

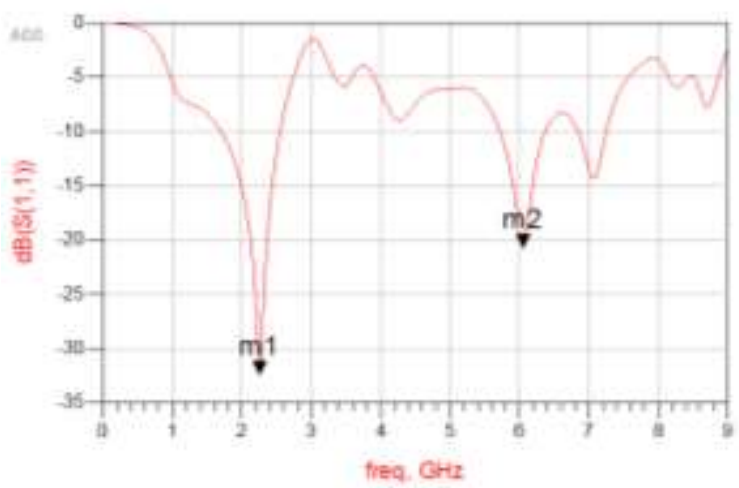

Fig.5(d). $180^{\circ}$ Fractal Ring MIMO Antenna 
The Fig.5(d) shows the return loss of $180^{\circ}$ Fractal Ring MIMO Antenna resonates at frequencies $2.3 \mathrm{GHz}, 6.1 \mathrm{GHz}$ and $6.9 \mathrm{GHz}$ with return losses $-32.381 \mathrm{~dB},-20.670 \mathrm{~dB}$ and $-14.9 \mathrm{~dB}$, respectively.

\section{ANALYSIS}

The radiation pattern of Single $0^{\circ}$ Fractal Ring Antenna and 0 Fractal Ring MIMO Antenna are depicted in Fig.6(a) and Fig.6(b).
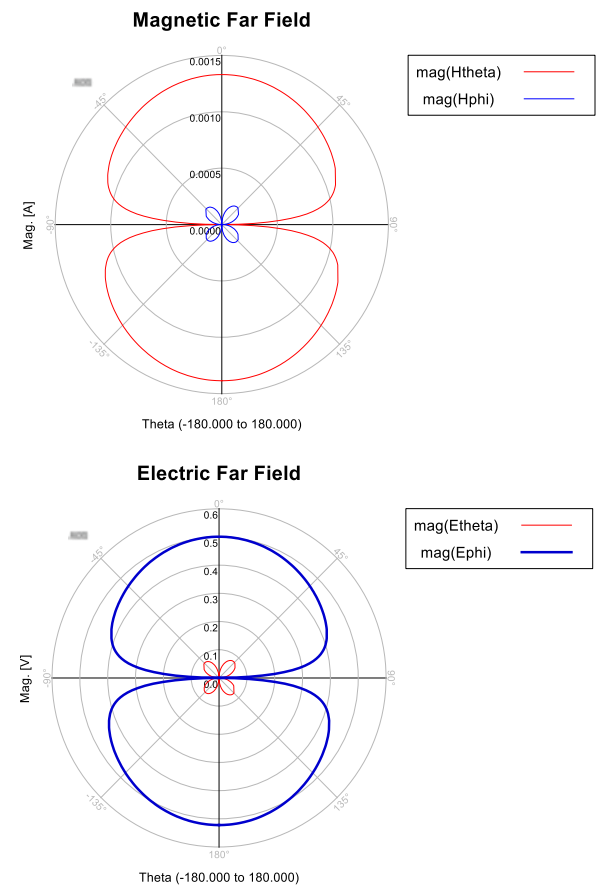

Fig.6(a). Radiation pattern of Single $0^{\circ}$ Fractal Ring Antenna

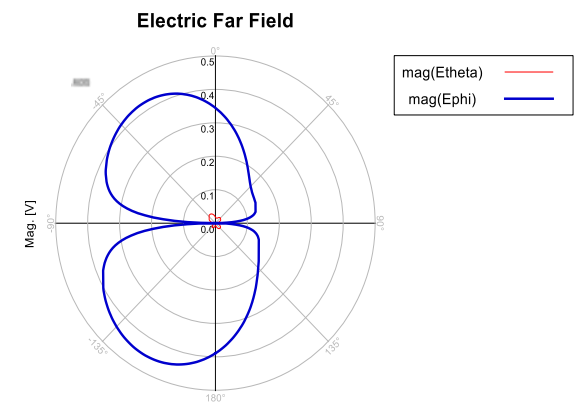

Theta (-180.000 to 180.000$)$

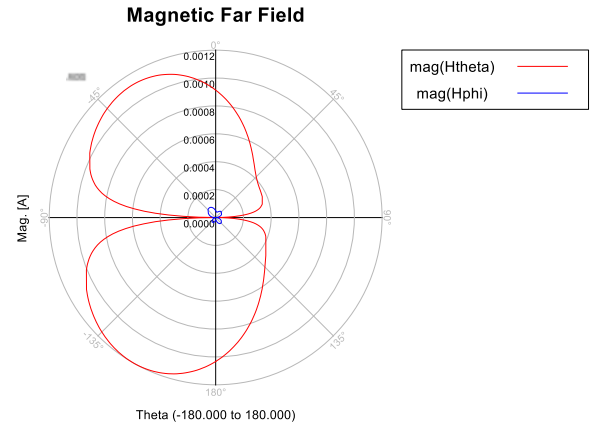

Theta (-180.000 to 180.000

Fig.6(b). Radiation pattern of $0^{\circ}$ Fractal Ring MIMO Antenna
The linear and circular polarisation of the single $0^{\circ}$ fractal ring antenna and $0^{\circ}$ fractal ring MIMO antenna are depicted below in the Fig.6(c) and Fig.6(d) respectively.
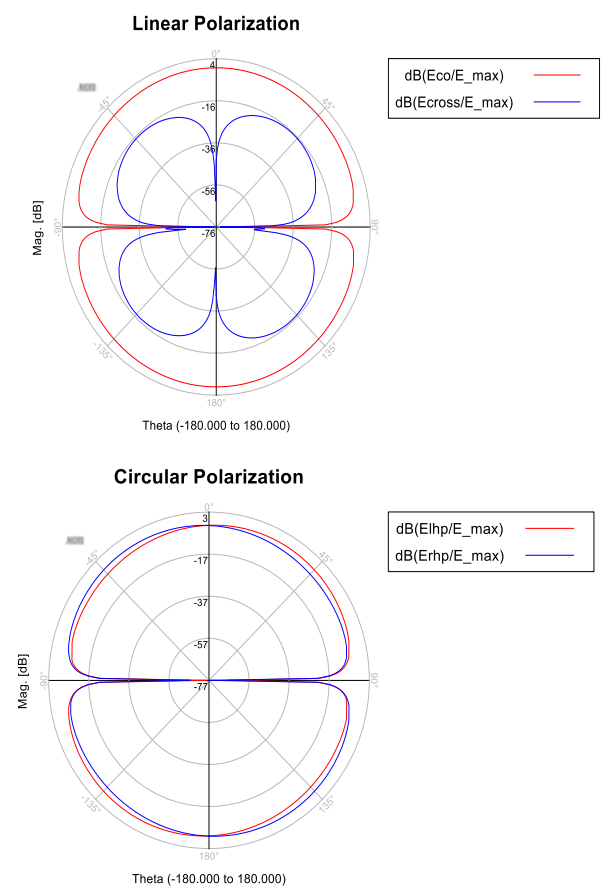

Fig.6(c). Linear and Circular Polarisation of single $0^{\circ}$ fractal ring antenna
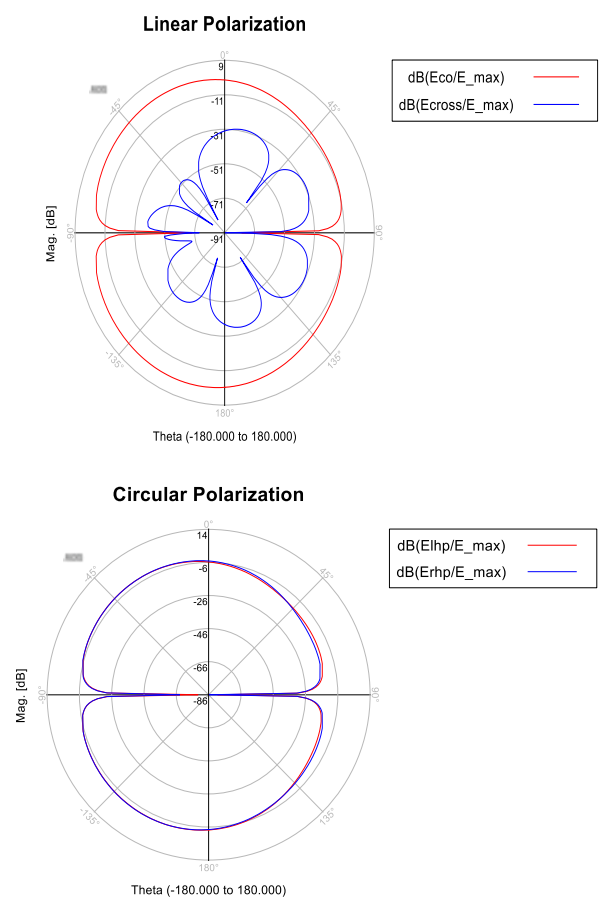

Fig.6(d). Linear and Circular Polarisation of $0^{\circ}$ fractal ring MIMO antenna

The radiation pattern of Single 180 Fractal Ring Antenna and $180^{\circ}$ Fractal Ring MIMO Antenna are depicted in Fig.6(e) and Fig.6(f) respectively. 

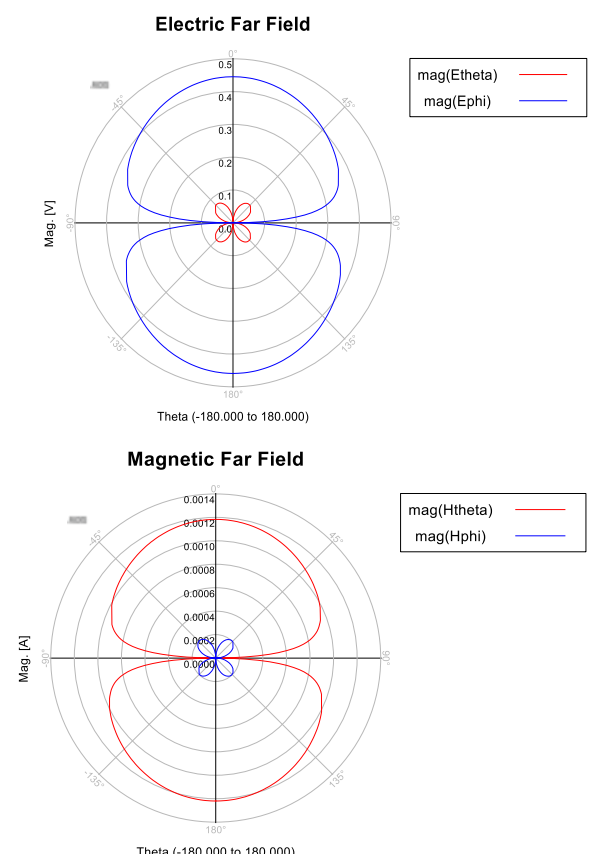

Fig.6(e). Radiation pattern of Single $180^{\circ}$ Fractal Ring Antenna

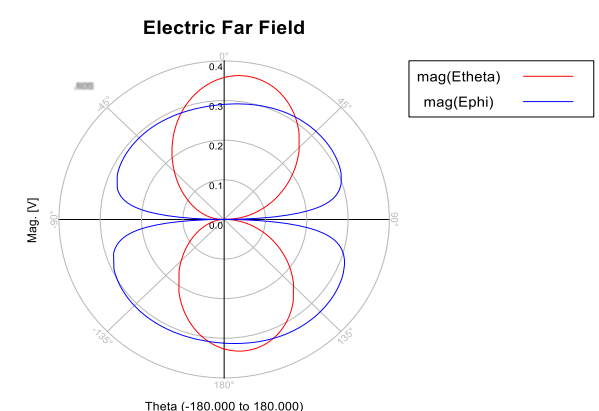

Magnetic Far Field

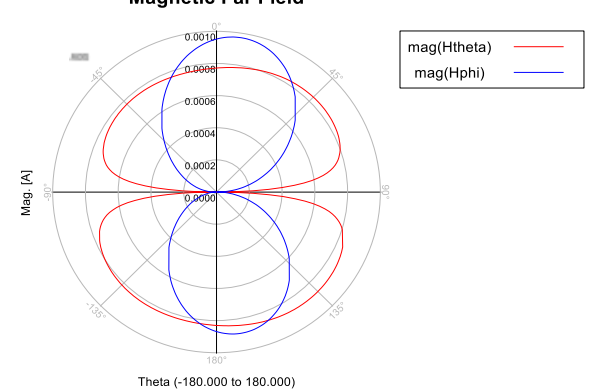

Fig.6(f). Radiation pattern of $180^{\circ}$ Fractal Ring MIMO Antenna

The linear and circular polarisation of the single $180^{\circ}$ Fractal Ring Antenna and $180^{\circ}$ Fractal Ring MIMO Antenna are depicted below in the Fig.6(g) and Fig.6(h) respectively.
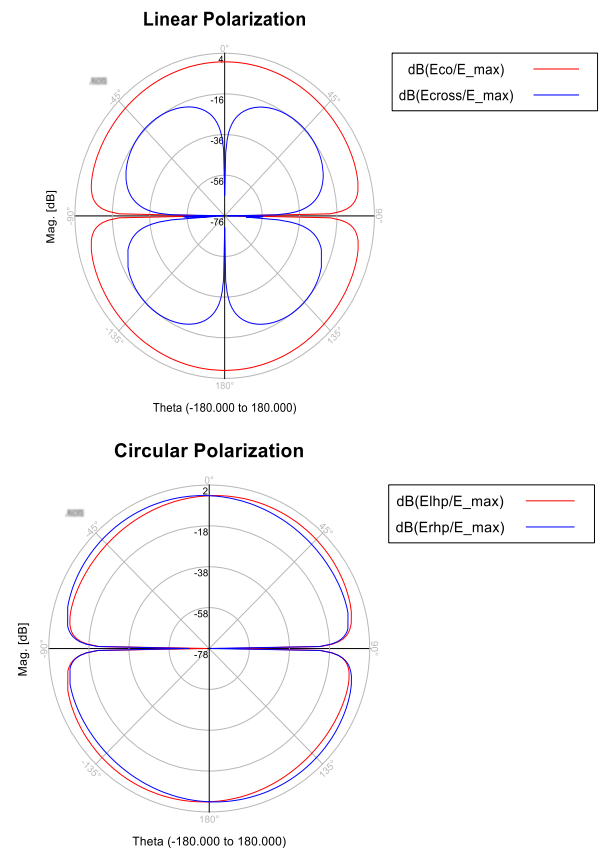

Fig.6(g). Linear and Circular Polarisation of single $180^{\circ}$ Fractal Ring Antenna
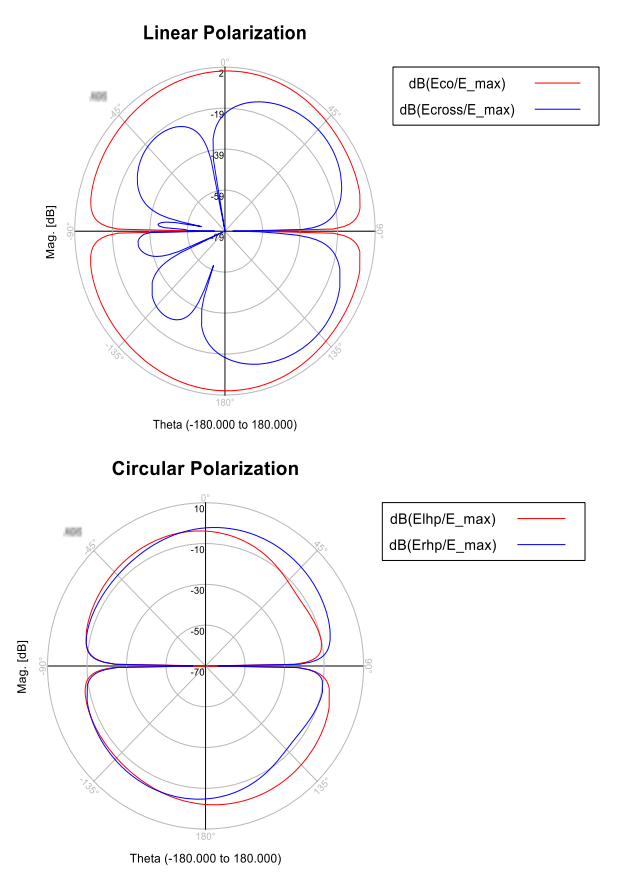

Fig.6(h). Linear and Circular Polarisation of $180^{\circ}$ Fractal Ring MIMO Antenna

Table.2. comparison of $0^{\circ}$ Fractal Ring Antenna

\begin{tabular}{|l|c|c|}
\hline \multicolumn{1}{|c|}{ Parameter } & Single $\mathbf{0}^{\circ}$ antenna & $0^{\circ}$ MIMO antenna \\
\hline Frequency & $3.8 \mathrm{GHz}$ & $3.8 \mathrm{GHz}$ \\
\hline Directivity & $4.2554 \mathrm{~dB}$ & $5.4 \mathrm{~dB}$ \\
\hline Radiation efficiency & $35 \%$ & $100 \%$ \\
\hline Gain & $0.299 \mathrm{dBi}$ & $5.4 \mathrm{dBi}$ \\
\hline Bandwidth & $347 \mathrm{MHz}$ & $2.6 \mathrm{GHz}$ \\
\hline
\end{tabular}


Table.3. comparison of $180^{\circ}$ Fractal Ring Antenna

\begin{tabular}{|l|c|c|}
\hline \multicolumn{1}{|c|}{ Parameter } & Single $\mathbf{1 8 0}^{\circ}$ antenna & $\mathbf{1 8 0}^{\circ}$ MIMO antenna \\
\hline Frequency & $4 \mathrm{GHz}$ & $4 \mathrm{GHz}$ \\
\hline Directivity & $5.7 \mathrm{~dB}$ & $4 \mathrm{~dB}$ \\
\hline $\begin{array}{l}\text { Radiation } \\
\text { efficiency }\end{array}$ & $27 \%$ & $67 \%$ \\
\hline Gain & $0.08 \mathrm{dBi}$ & $2.3 \mathrm{dBi}$ \\
\hline Bandwidth & $2.9 \mathrm{GHz}$ & $1.3 \mathrm{GHz}$ \\
\hline
\end{tabular}

The Table. 2 and Table. 3 shows the comparison of $0^{\circ}$ fractal ring MIMO antenna and $180^{\circ}$ fractal ring MIMO antenna. The bandwidth and radiation efficiency of $0^{\circ}$ fractal ring $\mathrm{MIMO}$ antenna is better with $180^{\circ}$ fractal ring MIMO antenna.

\section{CONCLUSIONS}

The proposed fractal ring MIMO antenna resonates at multiple frequencies and it can be used for various applications like GPS, WiMAX and Bluetooth. It has additional features like low cost, low profile, easily mounted and fabricated. The antenna is simulated from $0-10 \mathrm{GHz}$. The $0^{\circ}$ fractal ring MIMO antenna achieves better bandwidth and radiation efficiency compared with $180^{\circ}$ fractal ring MIMO antenna. Further improvements can be made by adopting different patch orientations in the monopole MIMO antenna.

\section{REFERENCES}

[1] Wael A.E. Ali and Ahmed A. Ibrahim, "A Compact Double Sided MIMO Antenna with an Improved Isolation for UWB Application", International Journal of Electronics and Communication, Vol. 82, pp. 7-13, 2017.

[2] Deepika Singh, Puran Gour and Rajeev Thakur, "Survey on MIMO Antennas for Mobile and Compensating User's Induced Loss", International Journal of Engineering
Research and Applications, Vol. 3, No. 1, pp. 2047-2051, 2015.

[3] Duong Thi Thanh Tu, Nguyen Van Hoc, Pham Dinh Son and $\mathrm{Vu}$ Van Yem, "Design and Implementation of Dual-Band MIMO Antenna with Low Mutual Coupling Using Electromagnetic Band Gap Structures for Portable Equipments", International Journal of Engineering and Technology Innovation, Vol. 7, No. 1, pp. 48-60, 2017.

[4] Kunal Srivastavaa, Ashwani Kumarb, Binod. K. Kanaujiac, Santanu Dwaria and Sachin Kumare, "Multiband Integrated Wideband Antenna for Bluetooth/WLAN Applications", International Journal of Electronics and Communication, Vol. 89, pp. 77-84, 2018.

[5] K. Vasu Babu and B. Anuradha, "Design of Multi-Band Minkowski MIMO Antenna to Reduce the Mutual Coupling”, Journal of King Saud University-Engineering Sciences, 2018

[6] Lingsheng Yang, Hongling $\mathrm{Xu}$, Jianping Fang and Tao $\mathrm{Li}$, "Four-Element Dual-Band MIMO Antenna System for Mobile Phones", Progress In Electromagnetics Research C, Vol. 60, pp. 47-56, 2015.

[7] Leeladhar Malviya, Rajib K. Panigrahi and Machavaram V.Kartikeyan, "Circularly Polarised 2x2 MIMO Antenna for WLAN Application", Progress in Electromagnetic Research C, Vol. 66, pp. 97-107, 2016.

[8] Sasmita Pahadsingh and Sudhakar Sahu, "Four Port MIMO Integrated Antenna System with DRA for Cognitive Radio Platforms", International Journal of Electronics and Communications, Vol. 92, pp. 98-110, 2018.

[9] T. Firmansyah, S. Suhendar, H. Herudin, R. Wiyardinata, M. Iman Santoso, Y. Rama Denny and T. Supriyanto, "Bandwidth and Gain Enhancement of MIMO Antenna by using Ring and Circular Parasitic with Air-Gap Microstrip Structure", Telecommunication, Computing, Electronics and Control Journal, Vol. 15, No. 3, pp. 1-8, 2017.

[10] Y.V.S.S. Satya Mitra, S.K. Kalisha, P. Raghavendra Kumar, P. Satish and K. Jagadeeshbabu, "Design of Novel Microstrip MIMO Antenna System with Improved Isolation", International Journal of Antennas, Vol. 2, No. 2, pp. 1-7, 2016. 